Plugin A, Trykoz L, Herasymenko O, Pluhin A, Konev V. Independent diagnostic computer systems with the ability to restore operational characteristics of construction facilities. Diagnostyka. 2018;19(2):11-21. http://dx.doi.org/10.29354/diag/83009.

DIAGNOSTYKA, 2018, Vol. 19, No. 2

ISSN 1641-6414

e-ISSN 2449-5220

DOI: $10.29354 / \mathrm{diag} / 83009$

\title{
INDEPENDENT DIAGNOSTIC COMPUTER SYSTEMS WITH THE ABILITY TO RESTORE OPERATIONAL CHARACTERISTICS OF CONSTRUCTION FACILITIES
}

\author{
Andrii PLUGIN ${ }^{1}$, Liudmyla TRYKOZ ${ }^{1}$, Oleh HERASYMENKO${ }^{1}$, Anton PLUHIN², Vitaliy KONEV ${ }^{3}$ \\ ${ }^{1}$ Ukrainian State University of Railway Transport, Department of Building Materials, Constructions and \\ Structures, Feuerbach sq., 7, 61050 Kharkiv, Ukraine, e-mail: aaplugin@ gmail.com, lvtrikoz@ukr.net, \\ gerasimenko.1978@gmail.com \\ ${ }^{2}$ National University of Radio Electronics, Department of of Artificial Intelligence, 14, Nauki ave., 61166 \\ Kharkiv, Ukraine, e-mail: anplug@gmail.com \\ ${ }^{3}$ PJSC "Ukrainian railway", Center of building-assembling works and exploitation of building and structures, \\ 7, Konareva str., 61052 Kharkiv, Ukraine, e-mail: ukrainoslav@ ukr.net
}

\begin{abstract}
Progress in modern engineering devices favours the development of independent computer systems of intelligent change management of operational characteristics of construction facilities. The article deals with the continuous control system (monitoring) of the soil moisture. The capillary sensor applied provides a far higher accuracy in determining the moisture than it is achieved by discrete determination of soil electrical characteristics which depend on the concentration and proportion of salts dissolved in the soil as well as the particle-size distribution. A flowchart of the diagnostic system was developed; it does not only transfer the data from the sensors, processes them and informs the operator, but also gives the possibility of autonomous inclusion of mechanisms to eliminate the emerged damages. Thus, while monitoring the soil moisture of hillsides, embankments and cuts slopes it prevents their shifts and other damages.
\end{abstract}

Keywords: NDT method, capillary sensor, soil moisture monitoring, remedial measures

\section{INTRODUCTION}

A considerable number of factors influence rail bed stability, which substantially hamper the forecasting of emergence and development of deformations and damages, which, in turn, leads to considerable expenses for repair works, losses due to the breaks in train traffic, increased costs for track maintenance and a low traffic safety level. To increase the reliability of track sections it is a necessary to create a monitoring system of the roadbed technical condition based on information technologies, which will consider the maximum possible number of factors influencing track stability. The monitoring makes possible to rank track sections by safety levels in terms of deformations emergence and to reveal the most vulnerable areas requiring additional inspection and stabilization.

Soils are capillary-porous materials for which one of the stability factors is an amount of moisture in pores. Accordingly, diagnostic techniques for roadbed structures can be based on measurements of soil electrical characteristics (resistance, capacity, dielectric permeability, and others) $[9,11$, 13]. At present the advance in diagnostic technical means allows designing more sophisticated systems of monitoring landslide processes. Study [5] presents the concept of environment for designing and testing distributed diagnostic systems. The equipment and systems for monitoring and diagnostics, included in the distributed diagnostic system, are called subsystems. Each element is a selected subsystem of the distributed diagnostic system. Locally, the element is linked with the subsystem which processes and collects the information from the data received from the subsystem. Globally, the element interacts with the other elements by transferring, receiving, processing and storing messages. Rapid development of mobile technologies of improved quality and higher data transfer rates encourages usage of mobile terminals for diagnostics [1]. It concerns diagnostics of both simple objects for routine usage and complicated (critical) objects. The study describes basic principles which allow the user to access the diagnostic data of a technical object wirelessly. Also, the study gives basic requirements for the well-developed user interface of the mobile application.

\section{THE ANALYSIS OF PREVIOUS RESEARCH}

Control systems are constantly being improved with diagnostic methods and information technologies. They include selection of information, special diagnostic systems, decision 
matching system and causal effect modelling. NDT methods are reviewed in [6]. The methodology, advantages and disadvantages along with up-to-date research on NDT methods are presented. Different damage levels having less dependence on inspector judgment are suggested. Moreover, a flow chart based on damage level along with NDT methods and potential remedial measures are proposed for periodic health monitoring of structures. Determination of the estimated performance for the developed diagnostic system is the most important stage of the development process. However, many well-known software engineering techniques cannot be immediately implemented for diagnostic systems.

Study [12] presents the technique for supporting diagnostic processes with a unique computer system which applies an additional reality, that is, the technology connecting the real and virtual realities. In the solution developed the diagnostic processes are running on the image display: component locations, diagnostic tasks, description hints, measured values, location of measuring points and 3-D component models. In this technology virtual objects are projected on the part of reality recorded by a camera or a set of cameras. The system operator obtains visual data from the projection equipment which is a part of the user interface. Based on the image projection of a technical device equipped with instructions and virtual objects, the operator analyses and interprets the state of diagnostic process, and then takes decisions regarding further problems described in the instruction. During the diagnostic process the feedback from the operator is visually signalled, thus reasoning the task improvement. As for the problems not connected with the element which generates the feedback, the accuracy of an executor is recognized by the user by means of comparing the physical state of the device with its visual image in the form of virtual objects and the text. The solution proposed is an important step towards improvements aimed at technical assessment of complicated engineering devices. The authors in [2] also propose the visually enriched approach for a user-oriented interface to facilitate semantic interoperability. The successful implementation of video surveillance technology for monitoring landslides and characteristics of the distance video surveillance system are also described in [15]. The real time images help to prevent and timely eliminate damages from unexpected geological landslides. Nonetheless, these methods allow controlling only the diagnostic process and cannot effect these changes in the diagnostic object.

The systems of monitoring and early prevention, though being able to collect constantly field data on landslide processes, generally, cannot independently detect and analyze landslide signs in real time. The monitoring system described in [7] is intended, firstly, for evaluating the risk of landslide and better interpreting the slope behaviour, which can contribute to decreasing economic losses and casualties from landslides. In particular, intelligent wireless sensor subsystems were distributed in the slope under observation for off-line collection, analysis and transfer of appropriate parameters of the environment in real time. The web application installed in the computer which is plugged to the sensor units on-site provides automatic distribution of parameters of the slope via internet. Study [10] proposes a draft program for monitoring landslide, collection, processing and analysis of data with the GPS technology. According to the analysis of the results of GPS monitoring, the landslide is in a constant-speed deformation stage. And precipitation is the major factor causing landslides. It is assumed that great attention should be paid to landslides during heavy showers, severe and prolonged rains in order to facilitate and prevent catastrophes. The significance of monitoring systems for landslides is also emphasized in [14]. An efficient monitoring system for landslides may not only solve engineering problems, but also decrease economic losses. Based on differences in objects, the monitoring systems for landslides can be divided into five categories: monitoring of deformation, monitoring of earthquake state, monitoring of tensions, hydrographic and environment monitoring. Thus, the selected monitoring techniques depend on monitoring objects. Hence, the diagnostic system development is a complicated engineering problem aimed at preventing damages from unexpected displacement of ground massifs.

\section{THE THEORETICAL BASIS FOR MONITORING SOIL MOISTURE}

A distinctive feature of the proposed monitoring system is so-called self-destruction of started negative changes in soils due to excessive moisture, and early prevention of possible effects from poor structural stability. The combination of the technique for soil moisture diagnostics [3] and the drainage method based on the capillary rise is taken as the basis [4].

Along capillary-porous bodies, such as concrete and soil, water moves under the influence not only hydrostatic pressure, but also various external and internal pressures [8]: capillary rise $p_{c r}$, osmotic pressure $p_{o s}$ and internal friction (viscous resistance of current) $p_{\text {if }}$

$$
\begin{gathered}
p_{o s}=\Delta c R T=R T \frac{\varepsilon \varepsilon_{0} \psi_{p}^{0}}{2 \pi d_{1} r F} ; \\
p_{c r}=\frac{2 \sigma}{r} \cos \theta ; \\
p_{i f}=\frac{2 \ln V}{r \delta} ;
\end{gathered}
$$

where $\Delta \mathrm{c}$ is the electrolyte concentration difference, $\mathrm{mole} / \mathrm{m}^{3} ; R$ is the universal gas constant, 8.31 $\mathrm{J} /($ mole $\cdot \mathrm{K}) ; T$ is the absolute temperature, $\mathrm{K} ; \varepsilon$ is the 
water dielectric conductivity, $80.1 ; \varepsilon_{0}$ is the electric constant, $8.81 \cdot 10^{-12} \mathrm{~F} / \mathrm{m} ; \zeta$ is the electrokinetic potential of capillary walls, $\mathrm{V} ; \psi_{p}{ }^{0}$ is the equilibrium electrical surface potential of capillary walls, $\mathrm{V} ; \delta$ is the thickness of diffuse double electric layer $\mathrm{m} ; r$ is the capillary radius, $\mathrm{m} ; d_{l}$ is the diameter of particles forming the capillaries, $\mathrm{m}$; $\sigma$ is the water surface tension, $0.073 \mathrm{~N} / \mathrm{m} ; \theta$ is the water contact angle of capillary walls; $l$ is the capillary length, $\mathrm{m} ; \eta$ is the water viscosity, 0.001 $\mathrm{Pa} \cdot \mathrm{s} ; V$ is the water flow in a capillary, $\mathrm{m}^{3} /$ year; $\chi$ is the specific electric resistance of a capillary system by saturated water, Ohm.m.

While modelling the work of capillary drainage we should consider that depending on specific conditions the operating pressure can have various signs and values: $p_{o s}$ acts only when there is a difference in concentrations of dissolved substances in the soil and the capillary filler; $p_{c r}$ acts only in presence of capillary meniscus (the flow from the device must output only to the air); $p_{\text {if }}$ always resists the water flow. Capillary drainage is possible for steady water flow. The steady-flow equation considering the most significant pressures is the basic physical and mathematical model of water drainage and soil dewatering processes

$$
\begin{gathered}
p_{o s}+p_{c r}=p_{i f}, \\
\Delta c R T+\frac{2 \sigma}{r}=\frac{2 l \eta V}{r \delta} .
\end{gathered}
$$

Thus, the flow speed in a capillary of the radius $r$ is

$$
V=\frac{(\Delta c R \operatorname{Tr} \delta+2 \sigma \delta)}{2 l \eta} .
$$

The water flow in a single capillary is

$$
Q=V S=V \pi(r-\delta)^{2},
$$

where $S$ is the cross-section area of the water flow, $\mathrm{m}^{2}$.

The number of capillaries in the system is

$$
N_{\text {cap }}=\frac{S_{0}}{S}=\frac{S_{0}}{\pi(r-\delta)^{2}},
$$

where $S_{0}$ is the cross section area of the capillary pipe, $\mathrm{m}^{2}$.

The total water flow is

$$
Q_{\text {total }}=V S N_{c a p}=\frac{(\Delta c R \operatorname{Tr} \delta+2 \sigma \delta)}{2 l \eta} S_{0} .
$$

A quantitative analysis of drainage for the whole system under development can be conducted on the basis of equation (9).

\section{STUDY OF SOIL SELF-DRAINAGE POSSIBILITY WITH CAPILLARY SENSORS}

The fundamental tasks in the investigation are search and selection of a simple dispersed material of high capillary absorption and capillary water rise, as well as the development of an effective layout and drainage techniques for water saturated soils by the method designed. As is known, the electric conductivity in dispersed systems, and consequently, their electric resistance is effected by the surface electric conductivity which, in turn, is mainly the result of counter ion transfer in the electrical double layer (EDL), where their concentration ten and hundred times higher than the volume concentration. Therefore, their electrical resistance does not depend on the chemical content and salt concentrations in the underground water. Besides, the surface conductivity depends on the number of the counter ions $\mathrm{H}^{+}$in diffuse part of EDL and its thickness, which, in turn, depends on the amount of water in the soil, that is, its moisture. It is significant that the soil electric resistance curve depending on moisture has a bend where its steep part turns into flat one, which testifies emergence of free water and transition of the soil in fluid state.

The basic part of capillary drainage is a pipe filled with well-wetting dispersed material with a developed capillary system of particles. The lower part of the pipe is intake and it is perforated, the upper one is transport and non-perforated. Among the materials used in the investigation were paper and cotton which proved to be improper as damageable and nondurable. Fibrous asbestos and crushed silica gel are well-wetting materials. They can form a developed capillary system, but cannot filter the water well. Hence, porous ceramics was chosen as drainage material. It filled the pipe in experimental facilities modelling various water drainage layouts (Fig. 1). The amount of water filtering along the pipe was measured with a graduated cylinder at certain times. Fig. 2 presents a kinetic curve of the water volume drained from the tank along the pipe filled with crushed brick of various grain sizes (Fig. 1c). As is seen from Fig. 2 the greatest consumption is for a filler of $0.315 \div$ $2.5 \mathrm{~mm}$ grain size, and the smallest consumption is for a filler of $0.315 \div 0.63$ and $1.25 \div 5 \mathrm{~mm}$ grain sizes. Thus, the optimal grain size of a filler in the experiment is $0.315 \div 2.5 \mathrm{~mm}$.

The experiment investigation into the time dependency of absorbed water volume was made to study the model reliability and application range of the capillary drainage. Fig. 3 gives kinetic curves of water drainage from water-saturated sand by various drainage layouts and from the water tank $V$ $=f(t)$. The research was conducted according to the diagrams given in Fig. 1. The quantitative capillary drainage characteristic can serve as the slope ratio $d V / d t, \mathrm{~m}^{3} / 24$ hours, or the tangent divided by the cross-section area of the pipe $\frac{1}{S} \cdot \frac{d V}{d t}, \mathrm{~m} / 24$ hours.

The first factor by physical content and dimension corresponds to the water flow; the second factor is a specific value corresponding to the coefficient of filtration and free-flow water permeability.

Therefore, the placement of drainage by the scheme presented in Fig. 1, $a$ is the most effective. 
a)

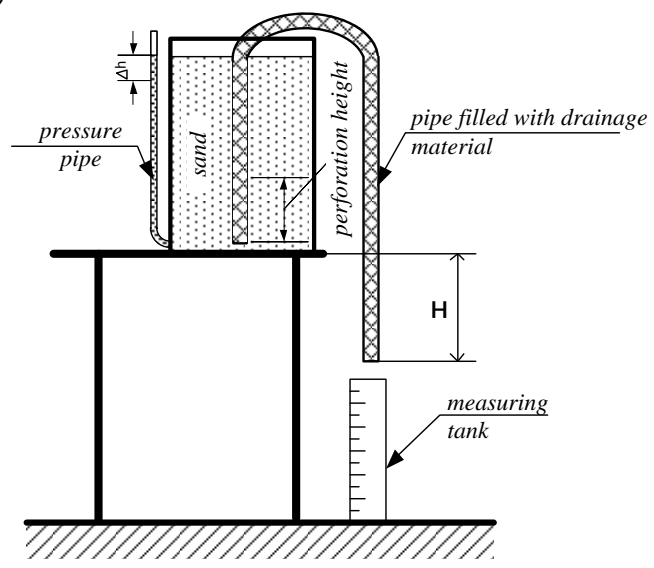

b)

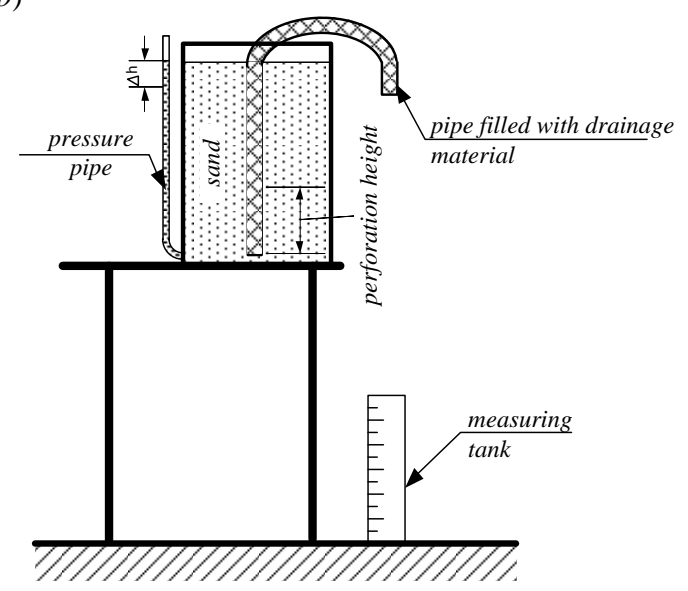

c)

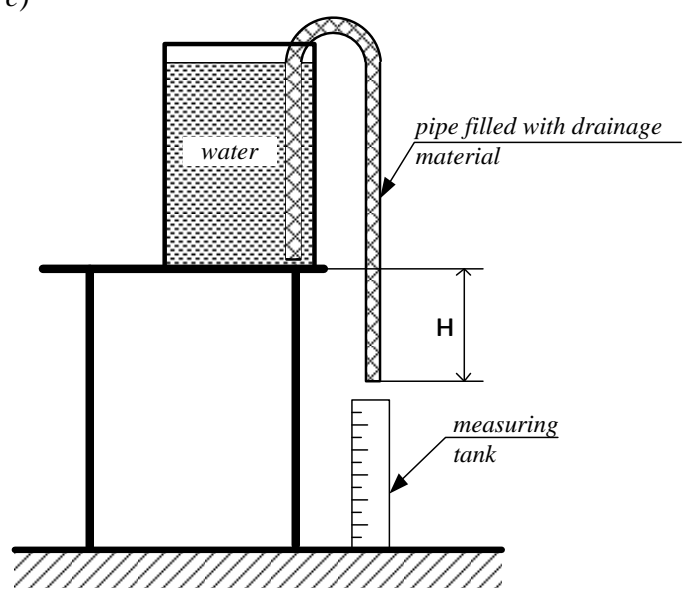

Fig. 1. The diagram of water drainage from saturated sand with capillary drainage: $a$ - water drainage is lower than the watered massif (the hydrostatic pressure contributes to dewatering); $b$ - water drainage is higher than the watered massif (the hydrostatic pressure hampers dewatering); $c$ - for research into experimental facility properties disregarding soil influence

\section{$V, \mathrm{~cm}^{3}$}

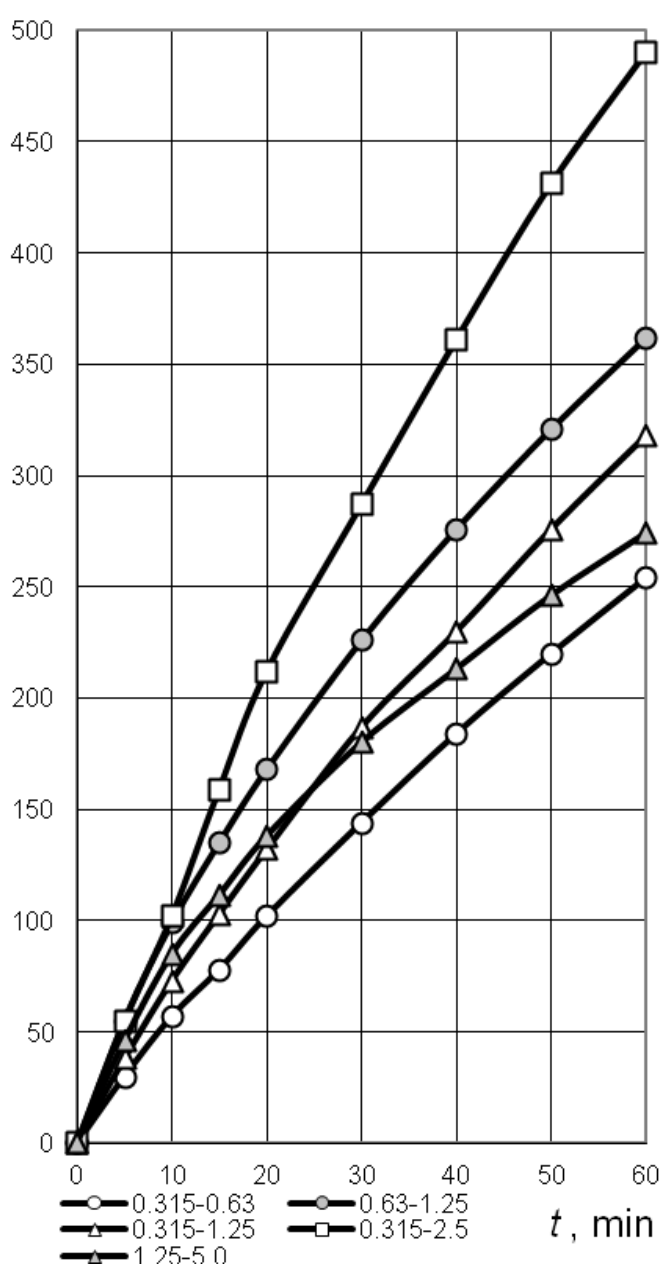

Fig. 2. The kinetic curves of water drainage from the tank by devices with various grain sizes of a filler

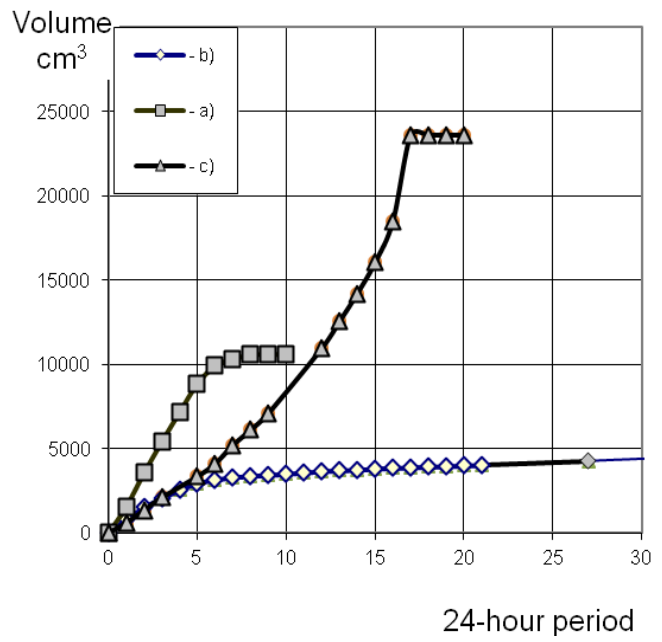

Fig. 3. The kinetic curves of water drainage from soil ( $a, b, c$ correspond to the diagrams of Fig. 1, $a, b, c$ ) 


\section{DEVELOPMENT OF THE SYSTEM MONITORING SOIL MOISTURE}

In order to implement the technique a unique coaxial capillary sensor was developed (Fig. 4) [3].

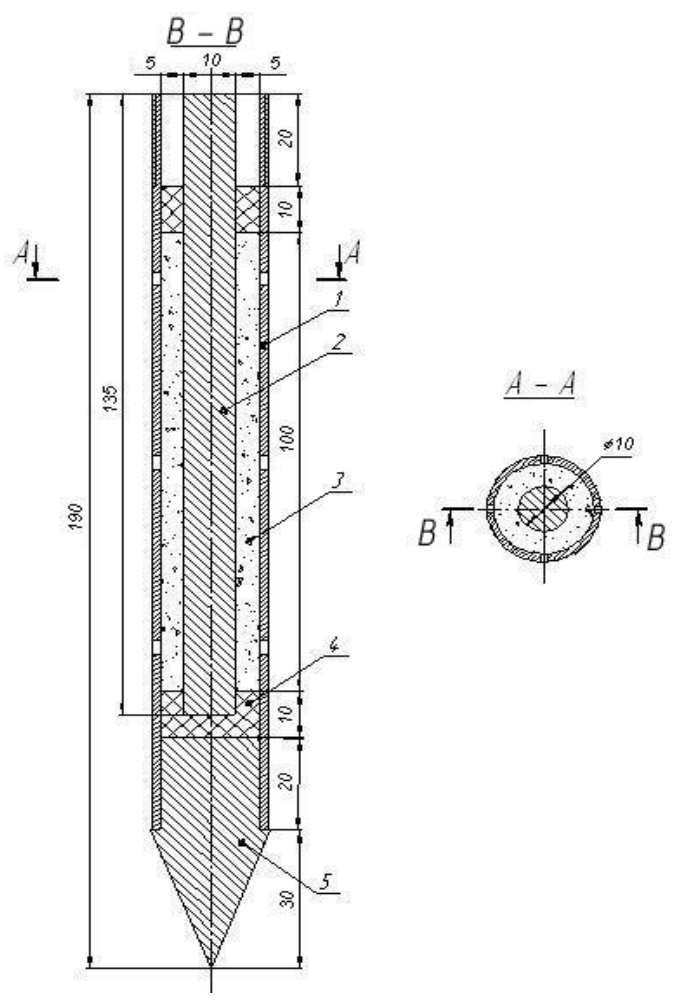

Fig. 4. The capillary coaxial sensor for soil moisture monitoring: 1 - external electrode; 2 - internal electrode; 3 - capillary filler; 4 polymer liners; 5 - cap

The electrode gap is filled with special capillary filler. The capillary filler through a punched external electrode is connected with the surrounding soil; its current moisture is determined by the capillary filler moisture and electrical factors of the sensor, the electrical resistance and capacity. The method provides a much higher accuracy in moisture determination than direct measurement of electrical characteristics of the soil influenced by fractional, salt composition and other factors. The sensors are mounted in places on the plan and underneath where deformations and damages due to soil excessive moisture are most possible. The sensors are plunged with a pipe string which is hammered to the planned depth, and then it is removed with a jack leaving the sensors and their conductors (Fig. 5). In order to measure the sensor resistances an ohmmeter or multimeter is used, thus providing a measurement range of $100 \mathrm{Ohm} \div 10 \mathrm{MOhm}$. The electric conductivity is measured with a device providing a measurement range of $1 \div 500 \mathrm{pF}$.

As the soil capacity and resistance depend not only on the moisture, but also the soil type (sands, clay sands, loamy soils, clays), there exists own characteristic dependency of resistance on moisture for each soil type. Consequently, the method, implemented as the basis for monitoring the soil moisture, requires preformed mathematical resistance-moisture equations. Based on the equations included in the software, the computer using the data on the soil resistance obtained from field sensors calculates the moisture, compares it with the admissible values for each soil type and provides recommendations to the operator or independent quick response system. The study presents experimental research about change of capacity and resistance due to sand moisture (Fig. 6).

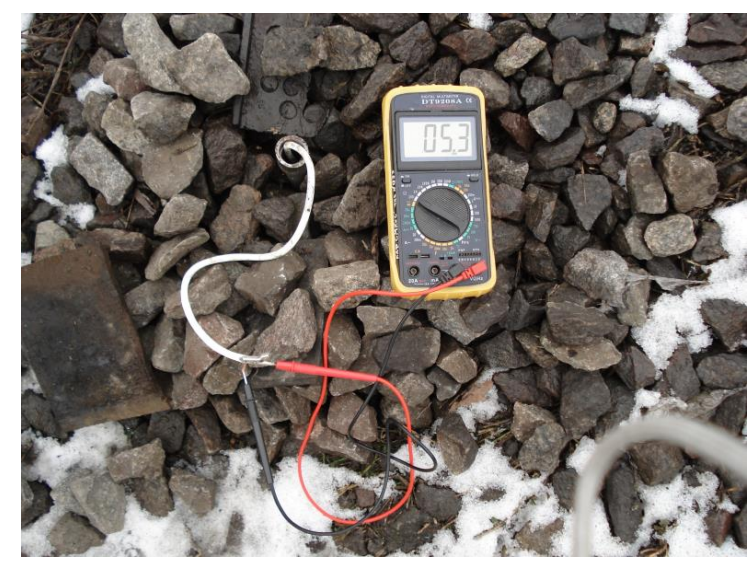

Fig. 5. The measurement of electrical resistance by the digital multimeter (an analog-to-digital

converter) of the sensor which is plunged using an inventory recoverable pipe string in the rail embankment at a depth of $10 \mathrm{~m}$

As is seen from the diagrams in Fig. 6 the dependency of the soil moisture on the sensor capacity is described by the square polynome

$$
y=-0.0272 x^{2}+5.772 x-286.28,
$$

and the soil moisture on the resistance - by the exponential equation

$$
y=47.363 x^{-0.56} .
$$

By the resistance (capacity) values with formulae (10) and (11) the soil moisture in each controlled point can be determined. The moisture values obtained are compared with the dangerous values which correspond to transfer of soils to fluid state, e.g., for clay it is $40 \div 50 \%$; for loamy soil it is $30 \div 40 \%$; for clay sand it is $20 \div 30 \%$; and for sand it is $23 \div 36 \%$. Higher soil moisture and its approaching to the dangerous values testify the possible emergence of deformations and damages. The soil moisture can be estimated by the ratio of the current resistance $R_{x}$ to the resistance $R_{0}$ in the point corresponding to fluidity. Thus, if $R_{x}$ exceeds $R_{0}$ $\left(R_{x}>R_{0}\right)$, the soil is considered structured, if it is lower than $\left(\mathrm{R}_{\mathrm{x}}<\mathrm{R}_{0}\right)$ it is considered floating and landslide hazard. The structuring degree of soil and its stability are determined by the ratio $R_{x} / R_{0}$, the higher it is the more structural and stable the soil is.

In order to confirm the adequacy of the capillary sensor developed in terms of reflecting changes in 
moisture, the field tests were conducted [4]. The sensors were located in the basement of an annex subject to uneven subsidence because of soils excessive moisture (Fig. 7).
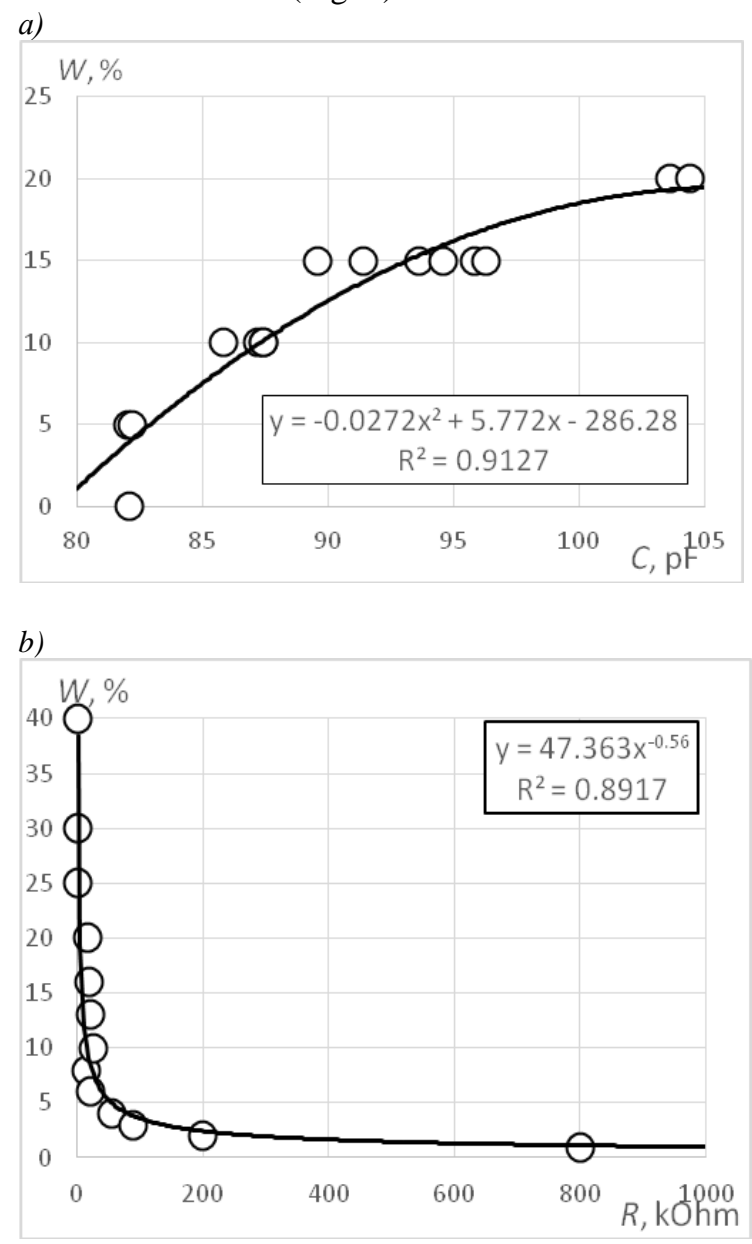

Fig. 6. The examples of correlation dependencies of the soil moisture $W$ on electrical characteristics of the sensor: $a$ - the electrical capacity $C ; b-$ the electric resistance $R$

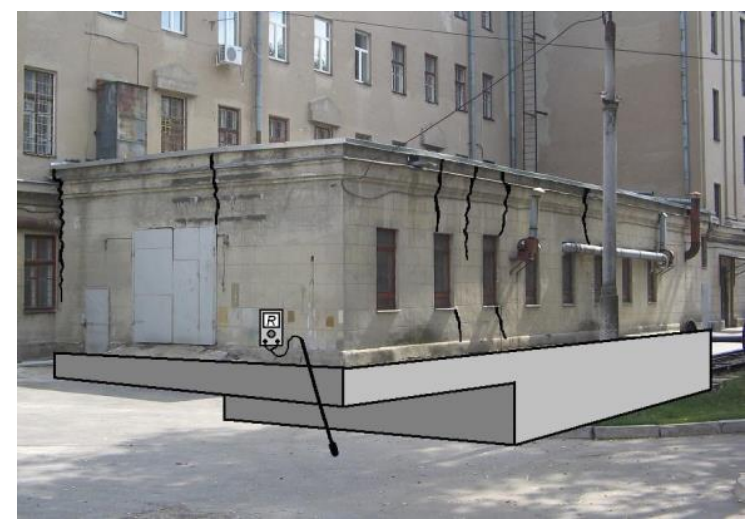

Fig. 7. The monitoring of the soil moisture of the annex foundation

The measured results of the electrical resistance of the sensor at direct (DC) and alternative (AC) currents and the soil moisture $\mathrm{W}$, calculated by the formula, are given on the diagrams in Fig. 8.
Among the measured results we can observe an abrupt decrease in resistance and, consequently, a higher moisture after a break of the underground pipeline of a heat network during the testing. Therefore, the sensor developed presents the actual data on changes in the soil moisture.

For continuous observations over the state of unstable slopes and embankments, study [4] presents a method developed for monitoring the soil moisture for potentially unstable roadbed embankments and landslide hazard slopes by means of stationary sensors (Fig. 9). The technique allows determining the soil moisture inside earthwork structures and ground massifs, where deformations and damages due to soil excessive moisture are considered to be possible. The technique is implemented by plunging a special capillary sensor in the soil, taking electrical measurements and assessing, by these data, the soil moisture and its rheological condition, plastic and fluid.

However, the diagram, as all the above mentioned, is a monitoring system and does not intended for elaborating solutions on restoration of lost operational properties and implementation of such decisions, i.e. for change management. There is a need for a system which will allow the dispatcher not only to take the right decision based on signals and sensors, but also to start prevention of emergency situations independently.

\section{DEVELOPMENT OF A DIAGRAM OF THE INDEPENDENT COMPUTER SYSTEM OF INTELLIGENT CHANGE MANAGEMENT OF OPERATIONAL CHARACTERISTICS OF CONSTRUCTION FACILITIES}

A flowchart of the operation algorithm of independent computer system of intelligent change management of operational characteristics of construction facilities is given in Fig. 10. Let us consider its work as a system for monitoring and management of the moisture soil state and the slope stability of the ground volume (fig. 9). The soil moisture determines the slope stability of the ground volume. If the moisture increases more than the normed limited values the destruction can occur, for example, a slope slide. The system functions the following way. The system uses coaxial capillary moisture sensors (fig. 4) which are placed on the soil volume (fig. 9), and analog-todigital converters (fig. 5). Previosly the normed limited values of the moisture ground are introduced in computer software. The computer with software turns on sensors in accordance to the previously assigned discrete mode. The values of the electrical resistance and capacity are determined by the sensors. These values with the analog-todigital converters get into the computers where they are transfomed into the moisture values according to formulas (10) and (11). 


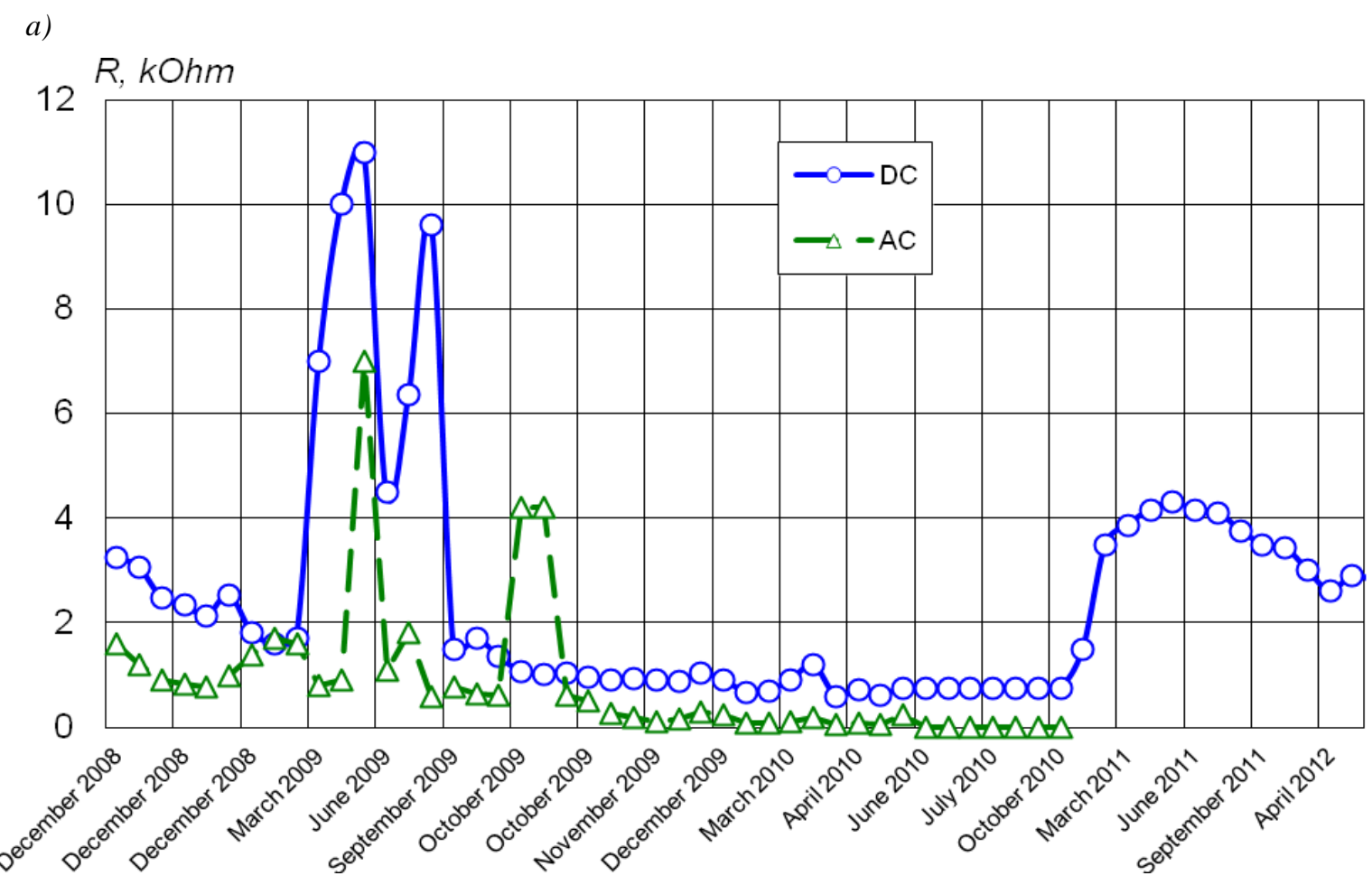

b)

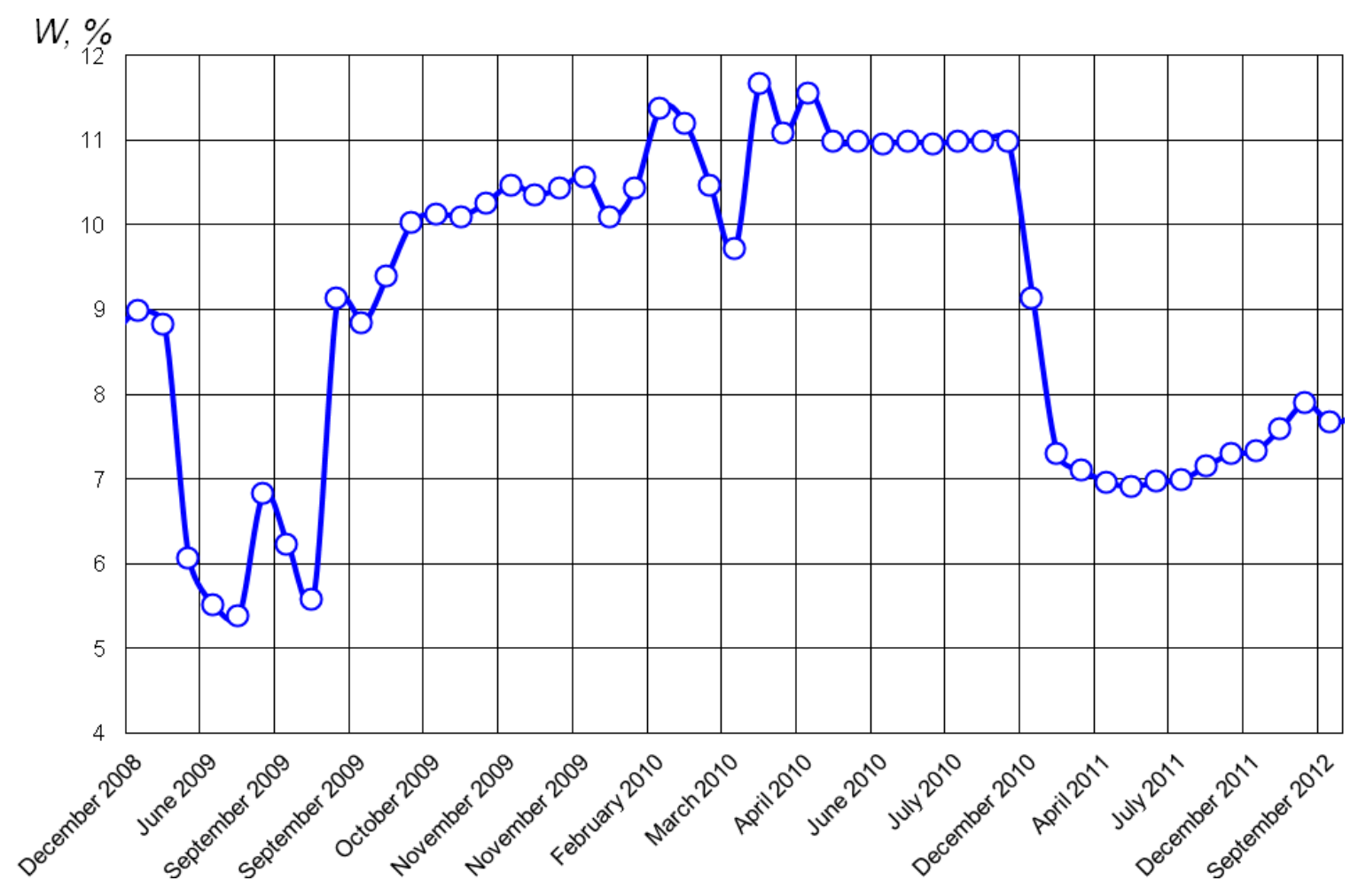

Fig. 8. History of the electric resistance R of the sensor (a), measured at direct current and soil moisture $(b)$ 
a)
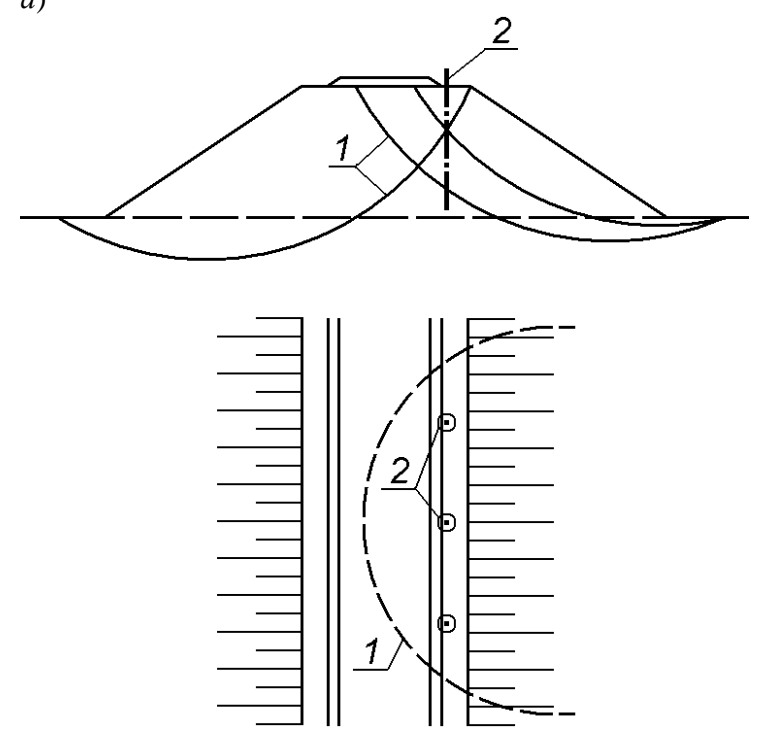

1 - possible shift surfaces of the slope; 2 sensor locations

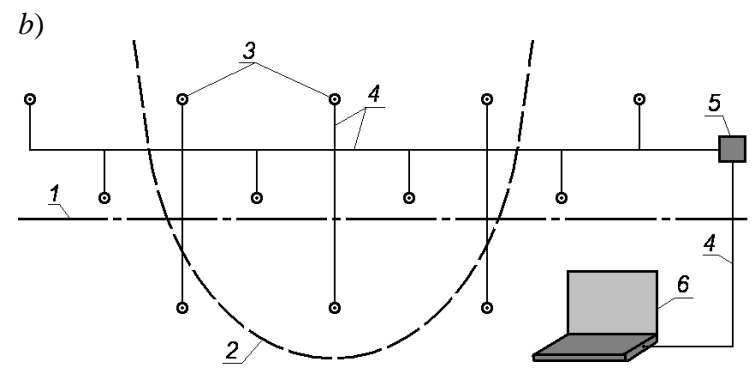

1 - rail track axle; 2 - supposed shift boundary; 3 - coaxial capillary sensors at a depth of the supposed sliding plate; 4 - links; 5 -devices for commutation, intensification and transformation of signals from the sensors; 6-dispatcher center

Fig. 9. The diagram of soil moisture monitoring: $a$ - unstable roadbed slopes; $b-$ landslide hazard slopes

The received values and sensor coordinates are the basis for 3D-model creating of the moisture isofields of the soil volume. The moisture isofields are displayed on the monitor screen. Next the computer software compares obtained moisture values with the specified limits. In case the moisture meets the specified limits (i.e. the lack of an exceedance) the system informs the oversight staff and turns off till the following switching on according to the given discrete mode. In case the moisture does not meet the specified limits the system informs the oversight staff about this and estimates the posibility of the automatic intensive correction of the operational characteristic indicator (the soil moisture) which exceeds the specified limits. This correction is possible if the system has the embedded executive tool for restoring the operational characteristics. The capillary drainages can be as the above mentioned tools (fig. 1), which are arranged in the soil volume and distributed between the capillary sensors (fig. 9). Under normal mode the capillary drainages dry the the soil volume. In case the system decides to reduce the moisture intensively the capillary drainages can be switched automaticaly to the electroosmotic drying mode. In this mode an external electrode of the capillary sensors is used as an anode, and the capillary drainage is used as a cathode.

After the electroosmotic drying during the determined time the drying is switched off, and the moisture sensors are switched on. In case the operational characteristic indicators exceed the specified limits (due to the lack of executive tools or the shortage of their productivity), and the automatic intensive correction is impossible then the system informs the operators and continues working in the expert mode. Using the special algorythms and data bases it generates the restoring of operational characterictic options, chooses the optimal option criteria, compares the options, offers the operator the most optimal of them, and provides recommendations about its realisations (a visit an emergency team, a drainage introduction or wells, a strengthening of the slope by a counterberm, geotextiles, a gabion, a retaining wall, a buttress, a screw injection pile, a bored pile, etc.). During the repair works the system operates in the moisture monitoring mode, after works are finished the system turns to the normal mode.

The devices for compulsory removal of water from water saturated soils by electroosmosis are taken as the executive restoration mechanisms for operational characteristics. The system of capillary sensors is preventive from accumulation of additional water in the soil, as it intensifies capillary water drainage from pores of earthwork structures. In case of excessive moisture and the critical electric resistance, the computer system not only informs the dispatcher, but also signals about external electrical field of the current strength $I$ fed to the sensor, which causes osmotic water transfer and prevents an abrupt loss of structural stability. Qualitatively the process is described by the Helmholtz-Smoluchowski equation [8]:

$$
\zeta=\eta \kappa \mathrm{Q} / \varepsilon \varepsilon_{0} \mathrm{I},
$$

where $\zeta$ is the electrokinetic potential of the soil particle surface, $\mathrm{V} ; \kappa$ is the specific electric conductivity of fluid, $\mathrm{Ohm}^{-1}$; $\mathrm{Q}$ is the fluid volume velocity, $\mathrm{m}^{3} / \mathrm{s} ; \varepsilon$ is the dielectric conductivity; $\varepsilon_{0}$ is the electric constant, $8.85 \cdot 10^{-12} \mathrm{~F} / \mathrm{m}$; $\mathrm{I}$ is the current strength, A. 


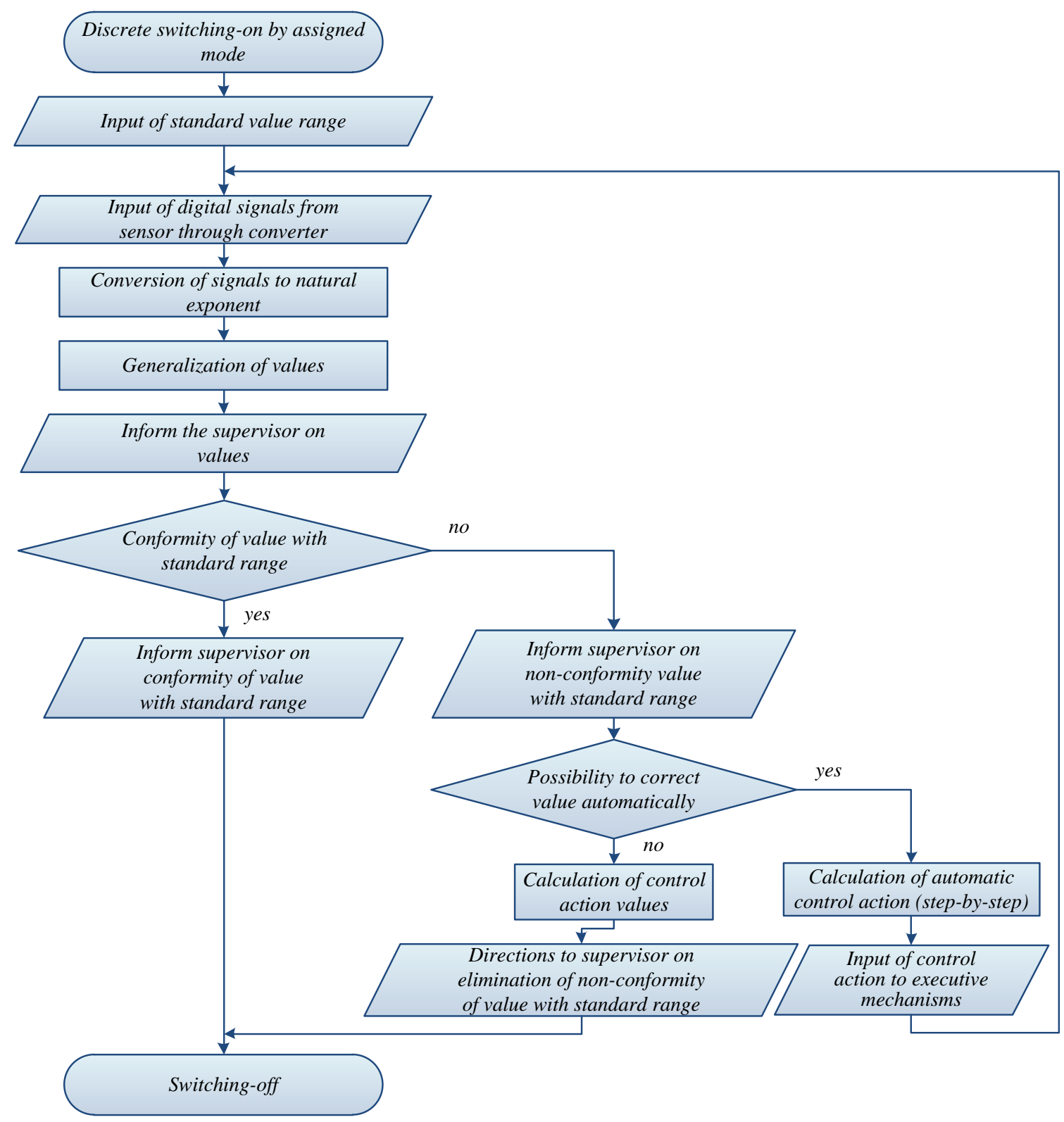

Fig. 10. The flowchart of the operation algorithm of independent computer system of intelligent change management of operational characteristics of construction facilities (by one factor)

Transform equation (12) by presenting the fluid volume velocity $\mathrm{Q}$ as the fluid volume $\Delta \mathrm{V}$, in the time $\Delta \mathrm{t}$ through the cross-section area $\mathrm{S}$ or differentially

$$
\mathrm{Q}=\Delta \mathrm{V} / \Delta \mathrm{t}=\zeta \varepsilon \varepsilon_{0} \mathrm{I} / \eta \kappa
$$

$$
\frac{\mathrm{dV}}{\mathrm{dt}} \cdot \frac{1}{\mathrm{~S}}=\frac{\zeta \varepsilon \varepsilon_{0}}{\eta \kappa} \cdot \frac{\mathrm{I}}{\mathrm{S}} .
$$

The current force I to the cross-section area ratio of the sample $\mathrm{S}$ is the current density $\boldsymbol{i}, \mathrm{A} / \mathrm{m}^{2}$. And finally we obtain

$$
\frac{\mathrm{dV}}{\mathrm{dt}} \cdot \frac{1}{\mathrm{~S}}=\frac{\zeta \varepsilon \varepsilon_{0}}{\eta \kappa} \cdot i,
$$

which means that the water volume through the roadbed embankment is directly proportional to the current density due to electroosmotic transport.
As we see, the right part of equation (15) includes measurable and well-known values which allow calculating a water flow in the roadbed embankment and a time needed for water drainage from pores, that is, to forecast a time to restore operational properties of earthwork structures.

\section{CONCLUSIONS}

1. The capillary coaxial sensor for monitoring soil moisture, which measures electrical properties (capacity and/or resistance) of the capillary filler between the core and punched sensor holder, was designed.

2. Due to theoretical and experimental research the authors chose the capillary filler for the sensor, 
crushed porous ceramics of $0.315-2.5$ grains, which provides both necessary sensitivity of the sensor, and its ability to be part of the sensor for draining water saturated soils by electroosmosis and capillary rise. The dependencies of the soil moisture $W$ on the electric capacity $C$ and the resistance $R$, including ones presented as equations were obtained; they can be used for computer programs to monitor soil moisture and stability of embankments, excavations, slopes and other soil massifs.

3. Based on the Helmholtz-Smoluchowski equation the dependency of speed factors of soil massif drainage on electric influence factors (current density) was obtained; they can be used in computer programs to calculate drainage control actions.

4. A block scheme of the monitor control system of soil moisture and stability of embankments, excavations, slopes and other ground massifs was developed; it is intended not only for informing the operator about maximum permissible values of soil moisture and dangerous losses of massif stability, but also for selecting and calculating independent feedback from the executive devices (e.g., drainage, injection fixation) which provide drainage and stability of the massif.

\section{REFERENCES}

1. Cholewa A. Mobile devices in diagnostic systems. Diagnostyka - Applied Structural Health, Usage and Condition Monitiring. 2012; 1(61): 59-64.

2. Khriyenko O, Terziyan V, Kaikova O. End-user facilitated interoperability in internet of things: Visually-enriched user-assisted ontology alignment. International Journal on Advances in Internet Technology. 2013; 6 (1/2): 90-100.

3. Patent 94875 UA G01N27/02. Techniques to measure and determine the soil moisture including depth conditions / UkrSART; A.A.Plugin, A.M.Plugin, O.S.Herasymenko, L.V.Trykoz, D.A.Plugin, O.A.Dudin, O.A.Pluhin, V.A.Liutyi. Ukrainian.

4. Plugin AA, Plugin AM, Trykoz LV, Herasymenko OS. Influence of watering and source currents on defects and deformations in the roadbed; monitoring soil moisture. Railway transport of Ukraine. 2010; 5: 5559. Ukrainian.

5. Rzydzik S. The conception of simulation environment for development and testing of distributed diagnostic systems. Diagnostyka - Applied Structural Health, Usage and Condition Monitiring. 2012; 1(61): 51-58.

6. SardarKashif Ur Rehman, Zainah Ibrahim, Shazim AliMemon, Mohammed Jameel. Nondestructive test methods for concrete bridges: A review. Construction and Building Materials, 2016; 107: 58-86. https://doi.org/10.1016/j.conbuildmat.2015.12.011.

7. Smarsly K, Georgieva K, König M. "An InternetEnabled Wireless Multi-Sensor System for Continuous Monitoring of Landslide Processes. International Journal of Engineering and Technology. 2014; 6 (6): 520-529.

8. Theoretical basics of hardening, stability, deterioration and durability of portland cement, concrete and their structures: monograph in 3 vols. V.1. Colloid chemistry and physico-chemical mechanics of cement concretes / A.N. Plugin, A.A. Plugin, L.V. Trykoz, A.S. Kahanovskyi, Al.A. Pluhin. Kiev: Nauk. dumka, 2011. Russian.

9. Wang L, Seko I, Nishie S, Uchimura T. Prefailure deformation monitoring of landslide and slope by using tilt sensors. Japanese Geotechnical Society Special Publication. 2016; 2(28): 1021-1024. http://dx.doi.org/10.3208/jgssp.jpn-048.

10. Wei Z, Chen FC, Zhan SL, Pan YH. GPS Application in Ginkgo Landslide Monitoring. Applied Mechanics and Materials. Trans Tech Publications. 2014; 624: 588-591.

http://dx.doi.org/10.4028/www.scientific.net/amm.62 4.588.

11. Wilkinson P, Chambers J, Uhlemann S, Meldrum P, Smith A, Dixon N, et al. Reconstruction of landslide movements by inversion of 4-D electrical resistivity tomography monitoring data. Geophysical Research Letters. 2016; 43(3): 1166-1174. http://dx.doi.org/10.1002/2015gl067494.

12. Wojcicki T. Supporting The Diagnostics And The Maintenance Of Technical Devices With Augmented Reality. Diagnostyka. 2014; 15 (1): 43-47.

13. $\mathrm{Xu} \mathrm{D,} \mathrm{Hu} \mathrm{X-Y,} \mathrm{Shan} \mathrm{C-L,} \mathrm{Li} \mathrm{R-H.} \mathrm{Landslide}$ monitoring in southwestern China via time-lapse electrical resistivity tomography. Applied

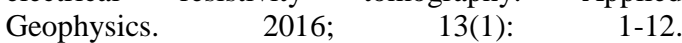
http://dx.doi.org/10.1007/s11770-016-0543-3.

14. Xu X, Shang M, Deng YH. Analysis about the Classification of Landslide Monitoring Method. Applied Mechanics and Materials. Trans Tech Publications. 2014; 638-640: 360-364. http://dx.doi.org/10.4028/www.scientific.net/amm.63 8-640.360.

15. Yin J, Wang HF, Wang SM, Xu F. Remote Video Surveillance Applications in Landslide Monitoring. Advanced Materials Research. Trans Tech Publications. 2012; 594-597: 1086-1092. http://dx.doi.org/10.4028/www.scientific.net/amr.594 $\underline{-597.1086 .}$.

Received 2017-11-02

Accepted 2018-01-16

Available online 2018-01-18

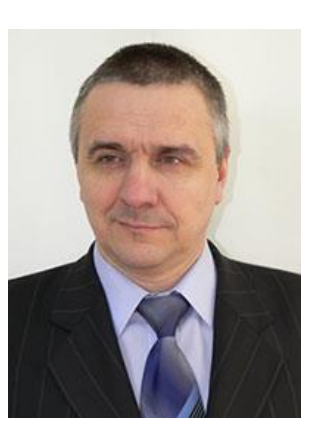

Andrii PLUGIN, Ph.D., D.Sc. is professor at the Department of Building Materials, Constructions and Structures, Ukrainian State University of Railway Transport. Main directions of scientific research: the development of theoretical and experimental foundations of composition, structure, properties, destruction, corrosion, durability, technology of concrete and reinforced concrete; reconstruction of operational properties and protection of building structures of buildings and structures. 


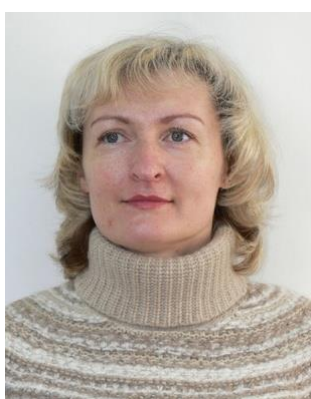

Liudmyla TRYKOZ, Ph.D., D.Sc. is professor at the Department of Building Materials, Constructions and Structures, Ukrainian State University of Railway Transport. Main directions of scientific research: research of the structure and properties of disperse systems and materials; development in the field of waste utilization in the production of building materials; diagnostic the state of engineering structures; the ground and roadbad stabilization.

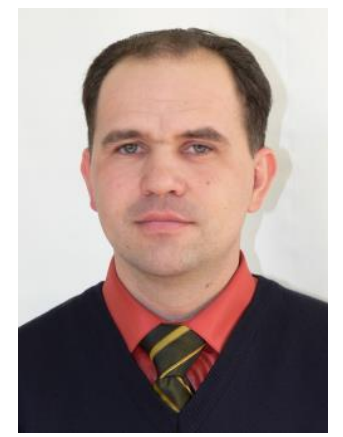

Oleh HERASYMENKO, Ph.D., is associate professor at the Department of Building Materials, Constructions and Structures, Ukrainian State University of Railway Transport. Main directions of scientific research: improvement of silicate solutions and technology of chemical bonding of ground soils and roadbad, methods for diagnosing soil conditions of foundation and roadbad, designing foundations.

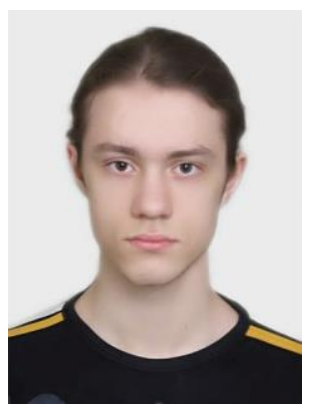

Anton PLUHIN, Eng., postgraduate student, Department of Artificial Intelligence, Kharkiv National University of Radio Electronics. Main directions of scientific research: Intelligent change management with the help of autonomous computer systems

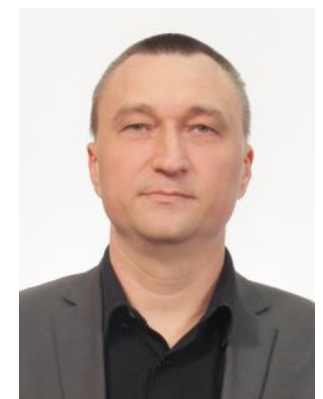

Vitaliy KONEV, Eng., Chief Engineer of operating subdivision "Kharkiv regional office" of branch "Center of building-assembling works and exploitation of building and structures" of PJSC "Ukrainian railway"”, Kharkiv, Ukraine. Main directions of scientific research: operation, repair and protection of buildings and structures of railway transport 